\title{
Conceitos relevantes de Custos: A visão de textos didáticos, o olhar da Teoria da Contabilidade e a percepção de discentes
}

\begin{abstract}
Raimundo Nonato Lima Filho Doutorado em andamento em Administração pela UFBA e Mestre em Contabilidade pela UFBA Professor da Universidade do Estado da Bahia - UNEB Rodovia Lomanto Junior, BR 407. Km 127. Senhor do Bonfim/BA E-mail:rnfilho@uneb.br

Adriano Leal Bruni Doutorado em Administração pela Universidade de São Paulo - USP Professor da Faculdade de Ciências Contábeis da Universidade Federal da Bahia UFBA Praça 13 de Maio, no 06. Praça da Piedade. Salvador/BA E-mail: albruni@gmail.com

Márcio Santos Sampaio Mestrado em Contabilidade pela Universidade Federal da Bahia - UFBA Rodovia Lomanto Junior, BR 407. Km 127. Senhor do Bonfim/BA E-mail:marcio_sampaio1@hotmail.com

Antonio Gualberto Pereira Mestrado em Contabilidade pela Universidade Federal da Bahia - UFBA Praça 13 de Maio, № 06. Piedade. Salvador/BA E-mail: gualberto_irece@yahoo.com.br
\end{abstract}

\section{RESUMO}

Um domínio apropriado dos conceitos básicos da Contabilidade de Custos e uma análise das suas características são essenciais para o desenvolvimento da Teoria Contábil e para a tomada efetiva de decisões. Este trabalho buscou comparar a apresentação de tópicos didáticos com conceitos atuais da Teoria de Contabilidade e a percepção dos discentes, aferindo a compreensão de alguns termos associados à Contabilidade de Custos e explorados no contexto da disciplina Teoria da Contabilidade. Foram discutidos os conceitos de ativos, receitas, despesas, ganhos e perdas. Examinou-se uma amostra composta por 591 alunos matriculados em Cursos de Ciências Contábeis que já haviam freqüentado a disciplina Teoria da Contabilidade em instituições de ensino superior localizadas na cidade de Salvador (BA). Os procedimentos quantitativos envolveram três fases distintas, formadas pela análise descritiva dos dados; pela compreensão das associações entre as respostas e o tipo de IES - apresentado como pública ou privada; pelo estudo da associação entre as respostas e a titulação do docente - separados em não titulados, mestres e doutores e; 
Conceitos relevantes de Custos: A visão de textos didáticos, o olhar da Teoria da Contabilidade e a percepção de discentes

Raimundo Nonato Lima Filho, Adriano Leal Bruni, Márcio Santos Sampaio, Antonio Gualberto Pereira

pelo uso da regressão logística que buscou entender como a acurácia dos conceitos aprendidos pode ser alterada a partir do tipo de IES ou da titulação do docente. Os resultados obtidos foram significativos para a titulação: à medida que evolui a titulação do docente, melhor o desempenho manifestado pelos discentes em relação ao domínio dos conceitos relevantes da Contabilidade de Custos. As constatações aqui observadas revelam a importância da titulação dos docentes de Teoria da Contabilidade e indicam que o avanço do estudo destes profissionais em cursos de Mestrado e Doutorado contribui para a melhoria do uso efetivo da Contabilidade de Custos.

Palavras-chave: Teoria da Contabilidade. Contabilidade de Custos. Conceitos Relevantes de Contabilidade de Custos. Ensino de Contabilidade de Custos.

\section{Relevant Concepts of Costs: The vision of textbooks, the look of Accounting Theory and the perception of students}

\section{ABSTRACT}

A proper domain of the basic concepts of Cost Accounting and analyze its characteristics are essential for the development of Accounting Theory and for effective decision making. This study aimed to compare the presentation of educational topics to current concepts of the Theory of Accounting and perceptions of students, assessing the understanding of some terms associated with Cost Accounting and explored in the context of discipline Accounting Theory. We discussed the concepts of assets, revenues, expenses, gains and losses. We examined a sample of 591 students enrolled in courses that Accounting had already attended the course Accounting Theory in institutions of higher education located in the city of Salvador (BA). The quantitative procedures involved three distinct phases, formed by the descriptive analysis, the understanding of associations between responses and the type of IES - presented as a public or private, by studying the association between the responses and titration of the teacher - not separated into titled, masters and doctors, for the use of logistic regression that sought to understand how the accuracy of concepts learned can be changed from the type of IES or the title of professor. The results were significant for the titration: as titration progresses the teacher, the better performance shown by students in the respect of the relevant concepts of Cost Accounting. The findings observed here indicate the importance of titling of teachers of accounting theory and indicate that advance the study of these professionals in the Masters and PhD courses helps to improve the effective use of Cost Accounting.

Keywords: Accounting Theory. Cost Accounting. Concepts Relevant Cost Accounting. Cost Accounting Education. 
Conceitos relevantes de Custos: A visão de textos didáticos, o olhar da Teoria da Contabilidade e a percepção de discentes

Raimundo Nonato Lima Filho, Adriano Leal Bruni, Márcio Santos Sampaio, Antonio Gualberto Pereira

\section{INTRODUÇÃO}

Um domínio adequado dos conceitos básicos da Contabilidade de Custos e uma análise das suas características são fundamentais para o desenvolvimento da Teoria Contábil e para um efetivo processo de tomada de decisão. De igual forma, o desenvolvimento das técnicas de identificação e mensuração dos itens dos relatórios contábeis contribui para o aperfeiçoamento do seu uso e para a melhoria dos processos de registro e gestão.

Para Watts e Zimmerman (1986), o objetivo da teoria contábil, pelo menos sob o enfoque positivista, consiste em explicar e predizer a prática contábil. A partir do momento em que se consegue explicar os fenômenos contábeis, com o embasamento da racionalidade natural, sob o enfoque da metodologia indutiva, além de fazer ciência, também desperta no pesquisador a necessidade de raciocinar, analisando as variáveis e suas relações de causa e efeito.

O domínio da mensuração apropriada do valor econômico de ativos, despesas, receitas, perdas e ganhos tornam-se cruciais, demandando a necessidade de estimular a pesquisa acadêmica na busca de metodologias de mensuração de ativos e passivos, que possam fornecer um valor mais aproximado da realidade do patrimônio de uma entidade. $O$ processo de tomada de decisões financeiras exige o conhecimento de valores econômicos apropriados, o que se torna cada vez mais demandado pelos usuários da Contabilidade.

O crescente número de investigações empíricas na área contábil vem instigando cada vez mais o desenvolvimento teórico do papel que a Contabilidade e, especialmente, a Contabilidade de Custos, exerce na sociedade e nas organizações. $O$ estudo de aspectos particulares da Teoria Contábil torna-se importante não apenas para pesquisadores e acadêmicos, mas também para aqueles cuja atuação profissional encontra-se relacionada à Contabilidade ou à Controladoria. A importância consiste no fato de que o arcabouço de sustentação das práticas contábeis encontra-se justamente na Teoria da Contabilidade. Uma das motivações deste trabalho parte justamente da constatação de que a superficial e genericamente aceita conceituação dos termos 
Conceitos relevantes de Custos: A visão de textos didáticos, o olhar da Teoria da Contabilidade e a percepção de discentes

Raimundo Nonato Lima Filho, Adriano Leal Bruni, Márcio Santos Sampaio, Antonio Gualberto Pereira

contábeis apresentados não contemplam as características de maior relevância para uma adequada compreensão.

Broedel (2002) destaca que a Contabilidade foi uma disciplina basicamente normativa, posto que preocupada em formular indicações sobre as melhores práticas profissionais foi assumindo um caráter mais científico. Trabalhos como os de Ball e Brown (1968) e Beaver (1968) motivaram quebras importantes de paradigmas, evidenciando uma análise prática da pesquisa contábil. Martins (2005) ressalta que, atualmente, nos principais periódicos da área contábil não se constata mais a presença de trabalhos acadêmicos que se resumem a sugerir alternativas, criar idéias e normas. Tornaram-se preponderantes trabalhos que se fundamentam em algum nível de empirismo, adicionando excelentes arcabouços teóricos.

A importância exercida pela Contabilidade nas organizações e os efeitos decorrentes do ensino da Teoria da Contabilidade sobre as práticas de profissionais ajudam a reforçar a importância do presente estudo, que busca entender como ocorre, de fato, a percepção de conceitos relevantes da Contabilidade de Custos, a exemplo de ativos, receitas, despesas, ganhos e perdas. De acordo com a Figura 1, apresenta-se 0 modelo de pesquisa utilizado.

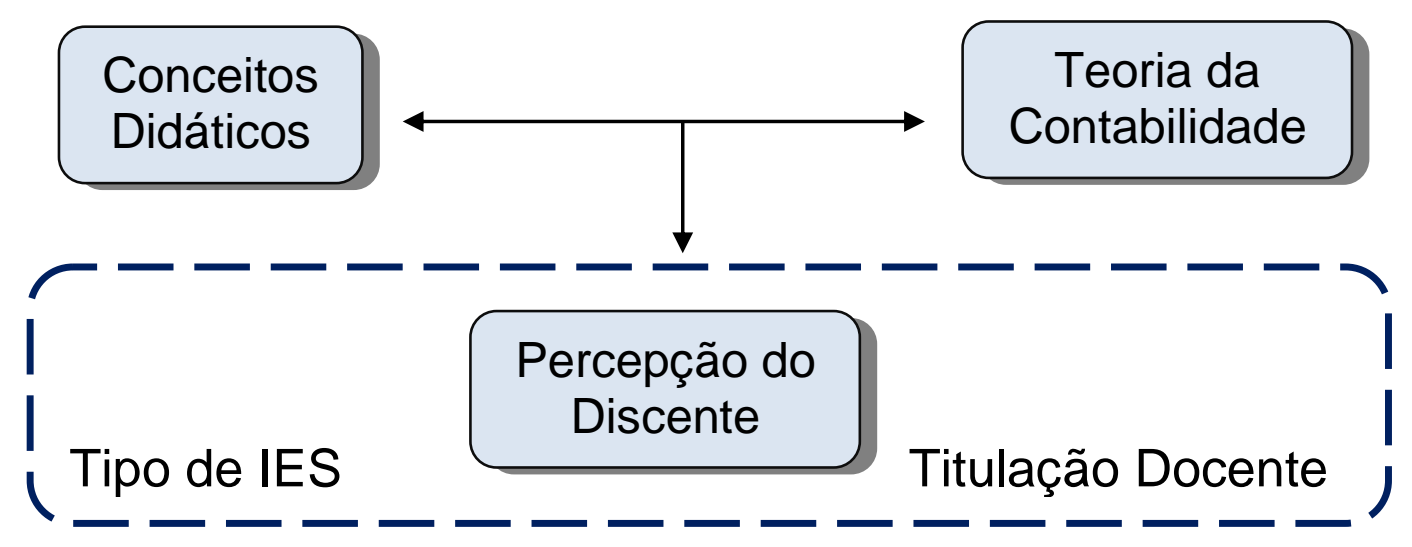

Figura 1: Modelo de Pesquisa

Fonte: elaboração própria.

A pesquisa busca confrontar a visão de textos didáticos voltados ao ensino de Custos com os conceitos atuais da disciplina Teoria da Contabilidade em cursos de 
Conceitos relevantes de Custos: A visão de textos didáticos, o olhar da Teoria da Contabilidade e a percepção de discentes

Raimundo Nonato Lima Filho, Adriano Leal Bruni, Márcio Santos Sampaio, Antonio Gualberto Pereira

graduação de Salvador, Bahia, no ano de 2009 e sua contribuição para a evolução da percepção destes conceitos, investigando se existe relação entre o conceito percebido e a titulação do docente da disciplina Teoria da Contabilidade e se existe relação entre o conceito percebido e o tipo da instituição de ensino, classificado como privada ou pública.

\section{PLATAFORMA TEÓRICA}

Para Leone (2000), a Contabilidade de Custos é parte integrante da Contabilidade, e corroborada por Medeiros (1997) como uma ciência que registra, estuda e analisa os fatos financeiros e econômicos que envolvem a situação patrimonial das pessoas físicas e jurídicas, sejam públicas ou privadas. A Contabilidade de Custos, portanto, é um instrumento que utiliza em seu desenvolvimento os princípios, os conceitos e os procedimentos fundamentais da Ciência Contábil (LEONE, 2000).

ludícibus (2009) classifica o conceito de ativo como o núcleo fundamental da Teoria Contábil que ainda se encontraria em plena discussão. Refere-se ao conceito de ativo e à sua mensuração, aspectos importantes, mas nem sempre devidamente compreendidos pelos estudantes na área de Ciências Contábeis. O conceito de ativo é apresentado como "o conjunto de bens e direitos de uma entidade" ou como "as aplicações de recursos" de uma empresa, sendo ensinado sem ensejar discussões a respeito da definição adequada para o termo. Para o autor, "é tão importante o estudo do ativo que poderíamos dizer que é o capítulo essencial da Contabilidade, porque à sua definição e avaliação está ligada a multiplicidade de relacionamentos contábeis que envolvem receitas e despesas" (IUDíCIBUS, 2009, p.129). Além de envolver valiosa discussão sobre as diferentes metodologias para a mensuração de elementos patrimoniais, o conceito de ativo é de utilidade para a definição de outros importantes termos como receitas, despesas, passivos, perdas e ganhos.

De acordo com Hendriksen e Van Breda (2007), os ativos são, na sua essência, reservas de benefícios futuros. Os autores também enfatizam a definição do Financial Accounting Standards Board (FASB), apresentada através do SFAC 62, onde os ativos 
Conceitos relevantes de Custos: A visão de textos didáticos, o olhar da Teoria da Contabilidade e a percepção de discentes

Raimundo Nonato Lima Filho, Adriano Leal Bruni, Márcio Santos Sampaio, Antonio Gualberto Pereira

são definidos como benefícios econômicos futuros prováveis, que são obtidos ou controlados por uma entidade em conseqüência de transações ou eventos passados. Nesta perspectiva, para o FASB, a incorporação de um benefício futuro provável aparece como característica essencial dos ativos. Caso não apresente tal propriedade, o FASB defende o não reconhecimento contábil da existência de tal ativo.

A principal característica relativa à capacidade de gerar benefícios futuros é conceituada por ludícibus (2009), para quem os ativos compreendem a capacidade de prestar serviços futuros à entidade que os controla individual ou conjuntamente com outros ativos e fatores de produção, capazes de se transformar, direta ou indiretamente, em fluxos líquidos de entrada de caixa. Todo ativo representa, mediata ou imediatamente, direta ou indiretamente, uma promessa futura de caixa.

Em contrapartida, em livros didáticos, a exemplo de Perez e Famá (2006), os ativos são considerados bens e direitos de uma entidade, expressos em moeda e à disposição da administração. Este conceito centra-se na questão da propriedade, desconsiderando aspectos como a posse e o controle. Essa visão não está alinhada às discussões atuais do conceito que envolve o ativo, que sob uma ótica econômica e financeira, são recursos controlados pela empresa e capazes de gerar benefícios futuros (entradas de caixa ou redução de saídas de caixa). Assim, pode ser considerado um ativo, todo e qualquer elemento com ou sem natureza física, que seja controlado pela empresa e que a ela proporcione a possibilidade de obtenção de fluxos de caixa. Segundo esta acepção, a mensuração aparece como uma forma de traduzir a capacidade de prestação de serviços e de geração de benefícios econômicos futuros em unidades monetárias. Desta forma, é esperado que a partir da mensuração seja possível apresentar um retrato da situação econômica de uma entidade, mormente por meio do patrimônio líquido.

O modelo contábil adotado no Brasil deixa de evidenciar certos ativos em virtude de dificuldades de reconhecimento ou da utilização de critérios de mensuração inadequados, não retratando o potencial presente apresentado pela organização. Como exemplo é possível citar a operação de leasing. 
Conceitos relevantes de Custos: A visão de textos didáticos, o olhar da Teoria da Contabilidade e a percepção de discentes

Raimundo Nonato Lima Filho, Adriano Leal Bruni, Márcio Santos Sampaio, Antonio Gualberto Pereira

Ainda, de acordo com Hendriksen e Breda (2007), o fato de um ativo ter potencial de gerar um benefício futuro provável, não o exclui da definição de ativos. A incerteza afeta a avaliação, mas só muda a natureza do item caso seja tão grande a ponto de fazer com que o benefício futuro esperado seja nulo ou negativo. Ainda, vale considerar que os benefícios econômicos devem resultar de transações ou eventos passados, bem como os recursos empregados deve estar sob o controle da entidade.

Goulart (2002), em uma pesquisa exploratória, chega à constatação de que definições superficiais do termo "ativo" não estavam contemplando as características essenciais deste e chega à conclusão de que os profissionais da área contábil possuem conhecimento apenas superficial do que seja "ativo", desconsiderando a característica principal deste item patrimonial quer seja, o direito específico a benefícios futuros.

Verifica-se, portanto, a importância fundamental da noção de "benefícios econômicos futuros" para uma correta definição e compreensão do conceito de ativo, indicando a inadequação de expressões simplórias como "aplicações de recursos" e "bens e direitos de uma entidade" para uma satisfatória percepção da natureza básica do referido conceito. Entende-se que uma compreensão satisfatória da natureza dos ativos, além de colaborar com o adequado tratamento e análise crítica de questões práticas da Contabilidade Aplicada, conferirá aos profissionais melhores condições para enfrentar os desafios atuais da Contabilidade.

De acordo com Pompermayer e Lima (2002), custos são ativos que se transformam em novos ativos, e corrobora com Martins (1997), Horngren (1998), Leone (2000) e Maher (2001) em relação aos conceitos contábeis discutidos didaticamente por estes autores, onde apresentam o ativo como um bem ou direito da entidade, um custo aplicado com a intenção de retorno positivo, ou seja, o lucro. Contudo, esta é uma perspectiva limitada do conceito de ativo, e amplamente discutida em sala de aula, ratificada pelos autores aqui discutidos.

Outro ponto relevante faz referência à compreensão de conceitos que afetam o cálculo do resultado. O correto entendimento das definições de receita, despesa, perdas e ganhos torna-se importante pelo efeito que estas definições trazem para a mensuração dos resultados das organizações. Porém, o profissional contábil pode 
Conceitos relevantes de Custos: A visão de textos didáticos, o olhar da Teoria da Contabilidade e a percepção de discentes

Raimundo Nonato Lima Filho, Adriano Leal Bruni, Márcio Santos Sampaio, Antonio Gualberto Pereira

apresentar falhas na sua formação acadêmica, comprometendo a efetividade de suas escolhas. É relevante entender as diferentes formas de conceituar, mensurar e reconhecer as variações favoráveis e desfavoráveis que ocorrem nas entidades. Dependendo do critério adotado na mensuração e reconhecimento das receitas, dos ganhos, das despesas e das perdas, o resultado líquido obtido poderá apresentar-se diferente, afetando acionistas, fisco e sociedade.

Numa visão didática, Leone (2000) salienta que alguns conceitos como, por exemplo, gastos, despesas, custos e perdas, são muitas vezes considerados como sinônimos, o que gera incompreensão das informações fornecidas pelos Sistemas de Custos, dificultando o alcance dos objetivos gerenciais da Contabilidade de Custos. Receitas e ganhos precisam ser diferenciados. De forma simples, e defendida por alguns autores, inclusive pelo FASB, as receitas estarão ligadas às atividades básicas da empresa enquanto que os ganhos têm uma vinculação periférica às essas atividades, não sendo o relacionamento com a atividade da empresa que os caracterizam. Tanto receita quanto ganho atuam no sentido de aumentar o resultado da empresa. Daí a importância do correto reconhecimento e mensuração desses itens, para evitar distorções e divulgação de resultados irreais. De certa forma, o reconhecimento e a mensuração, não só da receita, mas também do ganho, pode gerar resultados equivocados, quando não tendenciosos, gerando assimetria nas informações para os mercados, provocados pela discussão superficial destes conceitos em textos didáticos e em sala de aula.

Muitas vezes não se tem uma clareza definida sobre cada um dos conceitos. Por exemplo, muitos conceitos confundem a mensuração de receita com a definição de receita. De certo, ao analisar a natureza de uma receita, Hendriksen e Van Breda (2007) chamam a atenção de que "em nível mais fundamental, receita é aumento de lucro". Embora os próprios autores critiquem o fato de tentar se definir receitas e despesas a partir dos seus efeitos, ou seja, o resultado.

Na definição do FASB (1975 apud HENDRIKSEN; BREDA, 2007), "receitas são entradas ou outros aumentos de ativos de uma entidade, ou liquidações de seus passivos (ou ambos), decorrentes da entrega ou produção de bens, prestação de 
Conceitos relevantes de Custos: A visão de textos didáticos, o olhar da Teoria da Contabilidade e a percepção de discentes

Raimundo Nonato Lima Filho, Adriano Leal Bruni, Márcio Santos Sampaio, Antonio Gualberto Pereira

serviços, ou outras atividades correspondentes a operações normais ou principais da entidade". Essa definição parte da entrada do dinheiro na entidade, dentro de uma abordagem voltada ao foco de recebimentos à vista sem considerar o recebimento a prazo e características inerentes a este fim. Em uma visão mais moderna, tende-se a reconhecer as receitas como um fluxo, mas não um fluxo financeiro, e sim um fluxo de criação de ativos, como o produto da empresa. Segundo este conceito destaca-se, ainda, que para esse produto ser considerado receita faz-se necessário que ele tenha deixado a empresa, constituindo-se em um verdadeiro fluxo de saída. Niyama e Silva (2008), ao tratarem do tema, trazem a definição do IASB de que receitas são "aumentos nos benefícios econômicos durante o período contábil, sob a forma de entrada de recursos ou aumento de ativos ou diminuição de passivos, que resultam em aumentos do patrimônio líquido e não se confundem com os que resultam de contribuições dos proprietários da entidade".

Segundo a AAA (1957 apud IUDíCIBUS, 2009), receita "é a expressão monetária do agregado de produtos ou serviços transferidos por uma entidade para seus clientes durante um período de tempo" - uma definição restrita, embora concisa. Para Hendriksen e Breda (2007), a definição de receita como produto da empresa seria mais apropriada e mais correta do que o conceito para a AAA. Ainda assim, o conceito da AAA seria mais adequado que o conceito de fluxo de entrada proposto pelo FASB, em 1975. Mais importante do que ser uma entrada ou uma saída é o fato de que a receita não é simplesmente um fluxo de caixa.

A maioria das definições de receitas se prende no efeito desta sobre o patrimônio líquido, ao invés de descreverem a sua natureza. As definições correntes se referem à entrega de bens e serviços ao cliente. Esta definição pouco elucida sobre como se configura uma receita e o que a diferencia, por exemplo, de um ganho. Mesmo - Comitê de Conceitos Contábeis e Standards da Associação Americana de Contabilidade não contempla a questão da "gestação" da receita, se prendendo ao momento em que existe um valor de saída a ela atribuído. Para o referido órgão, a receita é a expressão monetária do agregado de bens serviços transferidos por uma entidade aos seus clientes durante um período de tempo. A definição em tela merece 
Conceitos relevantes de Custos: A visão de textos didáticos, o olhar da Teoria da Contabilidade e a percepção de discentes

Raimundo Nonato Lima Filho, Adriano Leal Bruni, Márcio Santos Sampaio, Antonio Gualberto Pereira

críticas uma vez que a expressão transferência de produtos e serviços é uma das etapas da geração da receita, representando a forma mais tradicional de reconhecimento da receita. O fato de a receita estar sendo reconhecida na transferência da posse não significa que não houve receita anteriormente.

Esta problemática está diretamente relacionada com a diferenciação entre reconhecimento e realização. O processo de agregação de valor contínuo aos bens e serviços por parte de uma entidade está relacionado com a realização da receita. Quando esta agregação de valor pode ser mensurada de maneira relativamente segura ocorre o seu reconhecimento.

Para Kam (1986) a renda não aparece de repente quando uma venda é feita, mas é gerada em incrementos de um processo contínuo. Portanto, é razoável ver a renda como um aumento em ordem gradual durante o período de produção; o evento mais importante do processo de ganho e o reconhecimento, mas só se houver provas suficientes para fazer isso.

Estas lacunas na literatura impactam de forma decisiva na resolução de problemas na prática. As empresas têm se valido de brechas na definição de itens relacionados à apuração do resultado para inflar suas receitas e para evitar incluir itens como despesa, sempre buscando maximizar resultados mesmo que se valendo de artifícios contábeis, a exemplo do gerenciamento de resultados. Neste contexto, Martinez (2001) ressalta que "é crucial assegurar a qualidade da informação contábil que é publicada, pois desta estará dependendo toda a prosperidade das empresas e, indiretamente, a da economia como um todo". Nem sempre o lucro é a medida mais coerente para a avaliação da tomada de decisão pelos stakeholders. Isso se evidencia não só pela questão do gerenciamento de resultados, mas também pelo fato de estes valores divulgados nem sempre representarem uma mensuração do resultado econômico da empresa.

Goulart (2008) se filia a esta linha de pensamento, ao mencionar que o resultado (lucro ou prejuízo) é uma das mais importantes informações produzidas pela contabilidade, e utilizada pelos analistas para avaliar o desempenho das empresas. Contudo, Martinez (2001) chama a atenção para o fato de que parte deste resultado 

Conceitos relevantes de Custos: A visão de textos didáticos, o olhar da Teoria da Contabilidade e
a percepção de discentes

Raimundo Nonato Lima Filho, Adriano Leal Bruni, Márcio Santos Sampaio, Antonio Gualberto Pereira

pode resultar de ajustes contábeis discricionários, sem qualquer correlação com a realidade do negócio, motivados por ações exógenas que podem influenciar os executivos a tomarem atitudes neste sentido.

No que concerne ao conceito de ganhos, há um consenso maior entre os autores, principalmente, no que tange às observações de sua aplicabilidade quando da ocorrência de operações extraordinárias às atividades normais das entidades. Para Hendriksen e Breda (2007), ganhos resultam de eventos favoráveis que não estão diretamente relacionados com a produção normal de receitas das empresas. Porém, ele coloca que a maior dificuldade consiste em distinguir o que é normal e o que é extraordinário na vida das entidades. Segundo Kam (1986), ganhos significam aumentos em ativos líquidos resultantes da realização de operações periféricas ou incidentais, ou outros eventos que podem estar em grande parte fora do controle da empresa. Resumidamente, a receita é o esforço da empresa que busca um resultado, seja essencial ou periférico; é a validação pelo mercado do incremento no potencial do ativo gerar benefícios futuros. O ganho, por sua vez, é um resultado positivo que independe inteiramente de qualquer esforço por parte da empresa.

Receitas, ganhos, despesas e perdas são influenciadores relevantes do lucro. ludícibus (2009) salienta que um dos maiores problemas é definir a magnitude e o momento da ocorrência das receitas e despesas e, por conseguinte, a definição de lucro.

As dificuldades de mensuração na contabilidade transpassam a barreira apenas do ativo e passivo, alcançando a idéia das despesas, conceito relativamente homogêneo na literatura. Schroeder; Clark e Cathey (2001) definem despesas como custos expirados na geração de receitas. Para Hendriksen e Breda (2007), despesa pode ser definida como o uso ou consumo de mercadorias ou serviços para a obtenção de receitas. As despesas são a contrapartida das receitas, participando da concepção de lucro. Hendriksen e Breda (2007) mencionam, ainda, que as despesas são medidas pela avaliação dos ativos usados ou consumidos, mas tal mensuração não as define, pois assim como as receitas, estas detêm um conceito abrangente e igualmente complexo em termos de consenso. Para Kam (1986), as despesas representam 
Conceitos relevantes de Custos: A visão de textos didáticos, o olhar da Teoria da Contabilidade e a percepção de discentes

Raimundo Nonato Lima Filho, Adriano Leal Bruni, Márcio Santos Sampaio, Antonio Gualberto Pereira

reduções no valor dos ativos ou aumento no valor das exigibilidades, tendo em vista à utilização de bens e serviços das operações principais ou centrais da entidade. Para ludícibus (2009), as despesas decorrem da utilização ou consumo de bens e serviços no processo de produzir receitas, podendo corresponder a gastos efetuados no passado, no presente ou que serão realizados no futuro.

A despesa é a concretização do esforço, em termos monetários, para a geração da receita. Reduz o patrimônio da empresa, o que é justificado pela promessa de geração futura ou imediata de receita que deve, por definição, suplantar as despesas e assim gerar a parcela do lucro. O fluxo de geração do lucro sofre intensa participação da despesa e, consequentemente, deve-se cercar-se de todos os mesmos cuidados voltados à receita, para caracterizar as despesas, diante de sua importância. $O$ fato gerador de despesa é o esforço continuado para produzir receita, já que tanto a despesa é conseqüência da receita, como a receita pode derivar da despesa, ou melhor, a receita futura pode ser facilitada por gastos passados, correntes ou futuros.

As perdas, diferentemente das despesas, são custos expirados que não são benéficos para as atividades produtoras de receita da empresa. Este é o entendimento da Associação Americana de Contabilidade citada por ludícibus (2006). A definição de Schroeder; Clark e Cathey (2001) coaduna-se com a da AAA, compreendendo as expirações de custo não geradoras de receitas. Segundo os entendimentos citados, um inventário destruído em um incêndio representa uma forma de "uso" do ativo, sendo o custo subjacente "expirado". Porém, diferentemente do conceito de despesa em que o custo expirado gera uma receita, neste caso a utilização do inventário, ou a expiração do custo, não contribui para a receita da empresa. Como resultado, esta expiração de custo, em particular, dá origem a uma perda, ao invés de uma despesa.

As perdas podem ser entendidas como eventos líquidos desfavoráveis, que nascem de atividades não geradoras de receitas normais da entidade. Entende-se por eventos líquidos desfavoráveis aquelas ocorrências não usuais, dissociadas das operações centrais da entidade, que refletem na participação dos proprietários. O FASB conceitua perdas como sendo decréscimos pela participação de transações periféricas ou incidentais de uma entidade, e em outras transações ou outros eventos e 
Conceitos relevantes de Custos: A visão de textos didáticos, o olhar da Teoria da Contabilidade e a percepção de discentes

Raimundo Nonato Lima Filho, Adriano Leal Bruni, Márcio Santos Sampaio, Antonio Gualberto Pereira

circunstâncias, afetando a entidade durante um período, exceto aqueles que resultam de despesas ou distribuição para proprietários.

As despesas estão voltadas à geração de receitas, por essa razão deverão ser com elas confrontadas, enquanto que as perdas não resultam em benefício da empresa, pelo contrário, é um efeito líquido desfavorável que não deriva das operações normais do empreendimento, por isso não há possibilidade de sua confrontação, sendo estas, reconhecidas pelo seu valor líquido.

\section{PROCEDIMENTOS METODOLÓGICOS}

O universo desta pesquisa corresponde aos alunos de Ciências Contábeis que já cursaram a disciplina Teoria da Contabilidade e que se encontravam regularmente matriculados na cidade de Salvador, Bahia, no primeiro semestre de 2009. Dados do Ministério da Educação extraídos do INEP - Instituto Nacional de Estudo e Pesquisas Educacionais, indicavam a existência de 28 cursos na cidade neste período. A partir deste universo, foi selecionada uma amostra de Instituições de Ensino Superior, IES, escolhidas por conveniência. Esta amostra de IES foi formada por duas instituições de ensino públicas e seis privadas. Posteriormente, obteve-se nas IES selecionadas outra amostra de alunos, composta por 591 estudantes, sendo 109 estudantes de IES públicas e 482 estudantes de IES privadas.

O instrumento de coleta empregado buscou investigar o domínio dos cinco conceitos: ativo, receitas, despesas, ganhos e perdas. Para cada um dos conceitos foram apresentadas quatro definições, sendo que o respondente deveria assinalar aquela que julgasse mais correta. As definições foram construídas com base nas controvérsias relatadas na revisão de literatura. Uma das alternativas era entendida como satisfatória (recebendo código 1). As demais foram entendidas como insatisfatórias (código 0). A média das respostas classificadas como satisfatórias possibilitou criar uma nova variável sintética, denominada média geral e que, com nota de 0 a 1, apresentada o conceito médio obtido pelo respondente em relação a cinco conceitos básicos da Contabilidade de Custos. 
Conceitos relevantes de Custos: A visão de textos didáticos, o olhar da Teoria da Contabilidade e a percepção de discentes

Raimundo Nonato Lima Filho, Adriano Leal Bruni, Márcio Santos Sampaio, Antonio Gualberto Pereira

Duas outras questões buscaram investigar o tipo da IES (0 privada ou 1 pública) e a titulação do docente da disciplina Teoria da Contabilidade (1 Graduação, 2 Especialização, 3 Mestrado e 4 Doutorado). A última questão precisou ser posteriormente codificada em três variáveis dummy, representando o fato de o professor ter evoluído na sua formação para especialista (1 sim, 0 não), mestre ( 1 sim, 0 não) ou doutor (1 sim, 0 não). A razão para a conversão em dummy residiu no fato de poder permitir uma classificação quantitativa para uma variável que seria originalmente qualitativa.

Os procedimentos quantitativos envolveram três fases distintas: (a) análise descritiva da amostra e das respostas; (b) análise da associação com o teste do quiquadrado entre respostas e tipo de IES ou formação do docente e com o teste t para comparar as médias dos diferentes grupos; (c) analise de regressão buscando explicar a média geral da compreensão dos conceitos com base no tipo de IES e titulação do docente.

\section{ANÁLISE DOS RESULTADOS}

A Tabela 1 apresenta a tabulação das características da amostra. Foram analisadas as respostas de 591 respondentes, sendo 482 (82\%) de IES privadas e 109 (18\%) de IES públicas. A maior concentração de respondentes em IES privadas buscou preservar a característica do universo, já que a maior parte dos cursos de Ciências Contábeis é ofertada em Salvador por IES privadas.

A análise da titulação dos professores da disciplina Teoria da Contabilidade revelou que 305 (52\%) respondentes tiveram docentes especialistas, $238(40 \%)$ tiveram aulas com mestres e 48 (8\%) com doutores. Nota-se a grande presença de especialistas, seguido por mestres. Poucos respondentes participaram de aulas de Teoria da Contabilidade com doutores. Esse número se explica porque somente uma faculdade apresentou professores com doutorado que lecionam essa disciplina. Dessa forma, verifica-se que dentre a amostra pesquisada, pouco se investe em docentes com 
Conceitos relevantes de Custos: A visão de textos didáticos, o olhar da Teoria da Contabilidade e a percepção de discentes

Raimundo Nonato Lima Filho, Adriano Leal Bruni, Márcio Santos Sampaio, Antonio Gualberto Pereira

níveis de titulação de doutores, já que é de fundamental importância uma instituição ter um docente com níveis mais elevados de titulação.

Tabela 1. Tabulação de titulação do professor e tipo de IES

\begin{tabular}{|c|c|c|c|c|c|}
\hline $\begin{array}{l}\text { Titulação do } \\
\text { professor }\end{array}$ & $\mathrm{Fi}$ & FI\% & Tipo de IES & $\mathbf{F i}$ & FI\% \\
\hline Especialista & 305 & 52 & Privada & 482 & 82 \\
\hline Mestre & 238 & 40 & Pública & 109 & 18 \\
\hline Doutor & 48 & 8 & Total & 591 & 100 \\
\hline Total & 591 & 100 & & & \\
\hline
\end{tabular}

O cruzamento das duas variáveis anteriores pode ser visto na Tabela 2. Nota-se que IES públicas apresentam professores com maior titulação. O teste da associação apresenta uma estatística do teste do qui-quadrado igual a 289,40 com um nível de significância igual a 0,0000, o que indica a força da associação entre as duas variáveis e possibilita afirmar a maior titulação dos docentes em IES públicas. O serviço público oferece estabilidade e em alguns casos melhores salários, por isso, professores com maior nível de titulação procuram desenvolver suas atividades em IES públicas.

A análise do domínio por parte dos respondentes dos cinco conceitos de ativo, receitas, despesas, ganhos e perdas pode ser feita com base nas duas tabelas apresentadas a seguir. As tabelas apresentam o resultado da tabulação cruzada do conceito entendido como satisfatório ou insatisfatório por tipo de IES e por titulação do docente. A força da associação pode ser analisada com base no teste do qui-quadrado.

Tabela 2. Tabulação cruzada Titulação versus Tipo de IES

\begin{tabular}{|c|c|c|c|c|}
\hline \multirow{2}{*}{ Titulação } & \multicolumn{2}{|c|}{ Particular } & \multicolumn{2}{c|}{ Público } \\
\cline { 2 - 5 } & $\mathrm{Fi}$ & $\mathrm{Fi} \%$ & $\mathrm{Fi}$ & $\mathrm{Fi} \%$ \\
\hline Especialista & 305 & 63 & - & 0 \\
\hline Mestre & 177 & 37 & 61 & 56 \\
\hline Doutor & - & 0 & 48 & 44 \\
\hline Soma & 482 & 100 & 109 & 100 \\
\hline
\end{tabular}

A análise do tipo de ensino pode ser visto na Tabela 3. Observa-se que em todos os casos a freqüência de respostas satisfatórias é sempre maior no ensino público. A 
Conceitos relevantes de Custos: A visão de textos didáticos, o olhar da Teoria da Contabilidade e a percepção de discentes

Raimundo Nonato Lima Filho, Adriano Leal Bruni, Márcio Santos Sampaio, Antonio Gualberto Pereira

estatística do qui-quadrado indica a significativa associação existente entre as variáveis.

Tabela 3. Tabulação para tipo de ensino versus resposta

\begin{tabular}{|c|c|c|c|c|c|c|}
\hline & \multicolumn{4}{|c|}{ Tipo de ensino } & \multirow{2}{*}{ Total } & Qui-q \\
\cline { 2 - 4 } \cline { 6 - 7 } & Particular & \multicolumn{2}{c|}{ Público } & & GL \\
\cline { 2 - 4 } & $\mathrm{Fi}$ & $\mathrm{Fi} \%$ & $\mathrm{Fi}$ & $\mathrm{Fi} \%$ & $\mathrm{Fi}$ & $\mathrm{Sig}$ \\
\hline Ativo & & & & & & 11,029 \\
\hline Insatisfatório & 378 & 78 & 69 & 63 & 447 & 1 \\
\hline Satisfatório & 104 & 22 & 40 & 37 & 144 & 0,001 \\
\hline Receita & & & & & & 13,650 \\
\hline Insatisfatório & 402 & 83 & 74 & 68 & 476 & 1 \\
\hline Satisfatório & 80 & 17 & 35 & 32 & 115 & 0,000 \\
\hline Despesa & & & & & & 32,950 \\
\hline Insatisfatório & 420 & 87 & 70 & 64 & 490 & 1 \\
\hline Satisfatório & 62 & 13 & 39 & 36 & 101 & 0,000 \\
\hline Ganho & & & & & & 14,111 \\
\hline Insatisfatório & 403 & 84 & 74 & 68 & 477 & 1 \\
\hline Satisfatório & 79 & 16 & 35 & 32 & 114 & 0,000 \\
\hline Perda & & & & & & 19,370 \\
\hline Insatisfatório & 397 & 82 & 69 & 63 & 466 & 1 \\
\hline Satisfatório & 85 & 18 & 40 & 37 & 125 & 0,000 \\
\hline Total & 482 & 100 & 109 & 100 & 591 & \\
\hline
\end{tabular}

Observação: Qui-q = estatística teste do qui-quadrado, $\mathrm{GL}=$ graus de liberdade, Sig. = nível de significância do teste do qui-quadrado.

Os resultados da Tabela 3 permitem destacar que os respondentes de IES públicas apresentam um melhor domínio conceitual de cada um dos cinco conceitos analisados. Alguns fatores implicam nesse desempenho, demonstrando que o ensino superior público procura um alinhamento mais próximo do desejável, preparando com maior eficiência seus discentes, equivalendo suas ementas de ensino às diretrizes de organismos nacionais e internacionais, tais como Resolução CNE/CES n 10/2004 e resoluções do IFAC, AICPA e AECC.

Observa-se, também, que o perfil do aluno determina o seu desempenho, na grande maioria, os alunos de IES pública desenvolvem atividades internas na Universidade ou em órgãos coligados como bolsistas, realizando pesquisas e estudos ligados ao seu curso, já os alunos de IES particular desenvolvem atividades que usualmente não tem ligação com seu curso de graduação. 
Conceitos relevantes de Custos: A visão de textos didáticos, o olhar da Teoria da Contabilidade e a percepção de discentes

Raimundo Nonato Lima Filho, Adriano Leal Bruni, Márcio Santos Sampaio, Antonio Gualberto Pereira

A Tabela 4 apresenta a tabulação cruzada das respostas por titulação do professor. Constata-se que à medida que se eleva a titulação do professor de Especialista para Mestre e para Doutor, aumentam as freqüências relativas das respostas satisfatórias, sendo que o aumento é maior quando a titulação evolui de Mestre para Doutor. Docentes com titulação de mestrado e doutorado possuem uma vida acadêmica mais atuante, ligada a produção de trabalhos científicos, exigindo constante atualização, fato que não se observa em docentes especialistas que na sua maior parte são profissionais que atuam na área, mas que não dedicam muito tempo para discussões sobre temas relevantes, por conseqüência, na melhor das hipóteses seus alunos terminam absorvendo somente o conteúdo adquirido na época de sua graduação, perdendo a oportunidade de discutir temas contemporâneos que envolvem a Ciência Contábil.

Tabela 4. Tabulação para titulação do docente versus resposta

\begin{tabular}{|c|c|c|c|c|c|c|c|c|}
\hline & \multicolumn{7}{|c|}{ Titulação do professor } & \multicolumn{2}{c|}{ Doutor } & & Qui-q \\
\cline { 2 - 9 } & Especialista & \multicolumn{2}{|c|}{ Mestre } & GL \\
\cline { 2 - 9 } & $\mathrm{Fi}$ & $\mathrm{Fi} \%$ & $\mathrm{Fi}$ & $\mathrm{Fi} \%$ & $\mathrm{Fi}$ & $\mathrm{Fi} \%$ & $\mathrm{Fi}$ & Sig \\
\hline Ativo & & & & & & & & 53,002 \\
\hline Insatisfatório & 258 & 85 & 171 & 72 & 18 & 38 & 447 & 2 \\
\hline Satisfatório & 47 & 15 & 67 & 28 & 30 & 63 & 144 & 0,000 \\
\hline Receita & & & & & & & & 50,186 \\
\hline Insatisfatório & 272 & 89 & 181 & 76 & 23 & 48 & 476 & 2 \\
\hline Satisfatório & 33 & 11 & 57 & 24 & 25 & 52 & 115 & 0,000 \\
\hline Despesa & & & & & & & & 76,535 \\
\hline Insatisfatório & 285 & 93 & 183 & 77 & 22 & 46 & 490 & 2 \\
\hline Satisfatório & 20 & 7 & 55 & 23 & 26 & 54 & 101 & 0,000 \\
\hline Ganho & & & & & & & & 39,220 \\
\hline Insatisfatório & 267 & 88 & 186 & 78 & 24 & 50 & 477 & 2 \\
\hline Satisfatório & 38 & 12 & 52 & 22 & 24 & 50 & 114 & 0,000 \\
\hline Perda & & & & & & & & 62,567 \\
\hline Insatisfatório & 261 & 86 & 188 & 79 & 17 & 35 & 466 & 2 \\
\hline Satisfatório & 44 & 14 & 50 & 21 & 31 & 65 & 125 & 0,000 \\
\hline Total & 305 & 100 & 238 & 100 & 48 & 100 & 591 & \\
\hline
\end{tabular}

Observação: Qui-q = estatística teste do qui-quadrado, $\mathrm{GL}=$ graus de liberdade, Sig. = nível de significância do teste do qui-quadrado.

A força da associação entre a titulação do docente e resposta apresentada na Tabela 4 pode ser vista nos valores altamente significativos dos testes t. Para cada um 
Conceitos relevantes de Custos: A visão de textos didáticos, o olhar da Teoria da Contabilidade e a percepção de discentes

Raimundo Nonato Lima Filho, Adriano Leal Bruni, Márcio Santos Sampaio, Antonio Gualberto Pereira

dos cinco conceitos, o nível de significância do teste foi aproximadamente igual a zero, o que indica freqüências estatisticamente diferentes. Devido a amostra ser segura e heterogênea e a pesquisa ter sido realizada de uma forma que pudesse garantir o mínimo de erro possível, observa-se que o qui-quadrado em todos os conceitos analisados é altamente relevante, comprovando que não há diferenças estatisticamente significativas.

As respostas apresentadas demonstraram que a maior parte da amostra pesquisada respondeu que ativo é bem ou direito da entidade, somente $24,4 \%$ dos alunos souberam responder que ativo é um beneficio futuro líquido, conforme reflexão desenvolvida neste trabalho. Resultado mais insatisfatório foi em relação ao conceito de receita, a grande maioria respondeu que é uma entrada de recursos ligada a atividade principal da empresa, quando na verdade é o esforço da empresa que busca um resultado, seja essencial ou periférico. Desempenho similar foi percebido no restante dos conceitos, evidenciando uma realidade alarmante da situação dos formandos em Contabilidade, já que se tratam de conceitos tão elementares.

A análise das respostas indica que, de maneira geral, os alunos pesquisados apresentaram definições acerca dos conceitos de forma pouco reflexiva e fora do contexto de discussões atuais, comprovando a necessidade dos docentes dessa disciplina alcançarem um maior alinhamento entre seu plano de aula e a Teoria da Contabilidade.

Ampliando a análise dos dados, uma nova variável foi criada, denominada média geral e que correspondeu à média das respostas tidas como satisfatórias em cada um dos cinco conceitos. $O$ valor 0 (zero) indica que nenhum dos conceitos apresentados pelo respondente foi considerado satisfatório. Por outro lado, o valor 1 (um) indica que todos os conceitos apresentados pelo respondente foram satisfatórios. A apresentação da média geral pode ser vista na Tabela 5. 
Conceitos relevantes de Custos: A visão de textos didáticos, o olhar da Teoria da Contabilidade e a percepção de discentes Raimundo Nonato Lima Filho, Adriano Leal Bruni, Márcio Santos Sampaio, Antonio Gualberto Pereira

Tabela 5. Análise cruzada da média geral por Titulação do docente e Tipo de IES

\begin{tabular}{|c|c|c|c|c|c|c|c|c|}
\hline Titulação & Média & $\mathbf{N}$ & Desvio & & IES & Média & N & Desvio \\
\hline Especialista & 0,117 & 305 & 0,245 & & Particular & 0,163 & 482 & 0,292 \\
\hline Mestre & 0,224 & 238 & 0,338 & & Pública & 0,339 & 109 & 0,408 \\
\hline Doutor & 0,554 & 48 & 0,416 & & Total & 0,196 & 591 & 0,323 \\
\hline Total & 0,196 & 591 & 0,323 & & & & & \\
\hline
\end{tabular}

Em relação à titulação do docente, percebe-se que a média aumenta com a elevação da titulação e um maior aumento ocorre quando a titulação é elevada de Mestre para Doutor. Analisando as médias com o teste $t$, tem-se um resultado na comparação entre Especialistas e Mestres para t igual a -4,105 (assumindo variâncias desiguais), com um nível de significância igual a 0,000. Comparando Mestres e Doutores, tem-se um valor para t igual a -5,154 (assumindo variâncias desiguais), com um nível de significância igual 0,000. Ou seja, os aumentos verificados nas médias são significativos tanto na evolução de Especialistas para Mestres como na evolução de Mestres para Doutores. O desempenho dos alunos que tiveram suas aulas ministradas por professores com maior nível de titulação, e dessa forma se pode afirmar que com domínio atualizado sobre o tema, foi superior àquelas cujas aulas foram ministradas por docentes de nível lato sensu.

Em relação ao tipo de IES, a média das IES públicas é maior do que a de IES privadas. O teste $\mathrm{t}$ para a comparação das médias entre particulares e públicas apresentou um valor igual a -4,277 (assumindo variâncias desiguais), com um nível de significância igual a 0,000 .

Com essa análise, teve-se a intenção de extrair uma média de desempenho dos alunos pesquisados por titulação do docente e pelo tipo da IES, e simular caso o questionário fosse uma prova de concurso público qual perfil analisado seria 0 aprovado. Dessa forma, observa-se que alunos de docentes doutores e ligados a IES públicas apresentaram melhor desempenho, sobretudo, se comparados aos discentes de IES particulares de professores especialistas.

A criação da variável média geral permitiu o uso da análise de regressão, com o objetivo de entender como a titulação do docente ou o tipo de IES influencia o domínio 
Conceitos relevantes de Custos: A visão de textos didáticos, o olhar da Teoria da Contabilidade e a percepção de discentes

Raimundo Nonato Lima Filho, Adriano Leal Bruni, Márcio Santos Sampaio, Antonio Gualberto Pereira

de conceitos contábeis relevantes, apresentado por meio da variável média geral. Como a menor titulação de docente da amostra foi especialista, o modelo de regressão construído pode ser apresentado na Equação 1 a seguir:

$$
Y=\hat{\beta}_{0}+\hat{\beta}_{1} I E S+\hat{\beta}_{2} \text { Mestre }+\hat{\beta}_{3} \text { Doutor }+\hat{u}
$$

Na Equação 1 o termo Y é a variável dependente, representada pela média geral dos conceitos satisfatórios. O termo $\beta_{0}$ representa o intercepto do modelo. Os termos $\beta_{1}, \beta_{2}$ e $\beta_{3}$ representam os coeficientes referentes às variáveis independentes ou explicativas do modelo, representadas por IES (0 particular e 1 privado), Mestre (0 Não e $1 \mathrm{Sim}$ ) e Doutor (0 Não e $1 \mathrm{Sim}$ ). O docente com titulação Especialista teve códigos 0 nas variáveis Mestre e Doutor. O docente com mestrado teve código 1 na variável Mestre e 0 na variável Doutor. $O$ docente com doutorado recebeu códigos 1 nas variáveis Mestre e Doutor. As variáveis dummy Mestre e Doutor capturam o efeito decorrente da evolução da titulação do professor de Teoria da Contabilidade. Por fim, o termo u representa o erro-padrão presente no modelo.

Os resultados da análise de correlação estão apresentados na Tabela 6. Os resultados indicam a importância da elevação da titulação do docente de Teoria de Contabilidade para a elevação da Média Geral dos conceitos satisfatórios. Os coeficientes são positivos e significativos, sugerindo que a elevação da titulação para Mestre e, depois, para Doutor contribui para um melhor domínio de conceitos importantes associados a ativo, receitas, despesas, ganhos e perdas. Por outro lado, os resultados da Tabela 6 também revelam a não significância do coeficiente da variável tipo de IES - o que seria possivelmente explicado pela multicolineridade existente entre as variáveis relativas à titulação do professor e ao fato da IES ser pública ou privada. 
Conceitos relevantes de Custos: A visão de textos didáticos, o olhar da Teoria da Contabilidade e a percepção de discentes Raimundo Nonato Lima Filho, Adriano Leal Bruni, Márcio Santos Sampaio, Antonio Gualberto Pereira

Tabela 6. Resultados da regressão múltipla

\begin{tabular}{|c|c|c|c|c|c|}
\hline \multirow{2}{*}{} & \multicolumn{2}{|c|}{$\begin{array}{c}\text { Coeficiente não } \\
\text { padronizado }\end{array}$} & \multicolumn{2}{c|}{$\begin{array}{c}\text { Coeficiente } \\
\text { padronizado }\end{array}$} & $\begin{array}{c}\text { Nível de } \\
\text { significância }\end{array}$ \\
\cline { 2 - 5 } & $\mathrm{B}$ & Erro padrão & $\mathrm{B}$ & $\begin{array}{c}\text { Erro } \\
\text { padrão }\end{array}$ & \\
\hline Constante & 0,117 & 0,017 & & 6,789 & 0,000 \\
\hline IES & $-0,071$ & 0,045 & $-0,085$ & $-1,591$ & $\mathbf{0 , 1 1 2}$ \\
\hline Mestre & $\mathbf{0 , 1 2 5}$ & $\mathbf{0 , 0 2 8}$ & $\mathbf{0 , 1 9 0}$ & $\mathbf{4 , 3 9 3}$ & $\mathbf{0 , 0 0 0}$ \\
\hline Doutor & $\mathbf{0 , 5 0 8}$ & $\mathbf{0 , 0 6 5}$ & $\mathbf{0 , 4 2 9}$ & $\mathbf{7 , 8 4 5}$ & $\mathbf{0 , 0 0 0}$ \\
\hline
\end{tabular}

A análise dos resultados da pesquisa indica que a relação desempenho do discente e titulação do docente é mais significativa que a relação desempenho do discente e tipo da IES, contudo, de forma geral, conceitos superficiais sobre os conceitos tratados nesse trabalho foram citados em todos os níveis, demonstrando a ineficiência do ensino, todavia percebe-se que nas IES públicas e com docentes com titulação de mestre ou doutor a freqüência de respostas satisfatórias foi mais acentuada.

\section{CONSIDERAÇÕES FINAIS}

Com vistas a tornar-se mais relevante para os modelos decisórios de seus diversos usuários, os estudiosos da contabilidade vêm empreendendo esforços para alargar sua base teórico-conceitual, sustentando-se em princípios mais amplos, tal como o princípio da essência sobre a forma. Este esforço tem se materializado em mudanças na legislação atual, a exemplo da Lei no. 11.638/07, que traz alguns avanços significativos quanto ao processo de reconhecimento, mensuração e evidenciação de informações contábeis. Um exemplo deste avanço é o próprio conceito de ativo que passa a englobar determinadas operações anteriormente tidas como operações de financiamento, como é o caso do leasing operacional.

Abordando o tema Teoria da Contabilidade por uma perspectiva teórica alternativa, o objetivo principal deste trabalho consistiu em avaliar o domínio dos conceitos básicos da Contabilidade de Custos pelos graduandos em Ciências 
Conceitos relevantes de Custos: A visão de textos didáticos, o olhar da Teoria da Contabilidade e a percepção de discentes

Raimundo Nonato Lima Filho, Adriano Leal Bruni, Márcio Santos Sampaio, Antonio Gualberto Pereira

Contábeis de IES de Salvador. Tal meta se justificou pela vontade de conhecer os fatores que possivelmente interferiam na percepção desses conceitos, através de duas variáveis independentes.

Os resultados obtidos indicam uma percepção formal pouco reflexiva e desatualizada dos conceitos. Docentes de Teoria da Contabilidade e Contabilidade de Custos precisam investir maiores esforços no ajuste das suas agendas didáticas. Testes de qui-quadrado, testes t e modelo de regressão múltipla permitem concluir que as variáveis "titulação do docente" e "tipo da IES" influenciam na ocorrência de respostas desfavoráveis acerca dos conceitos básicos da Contabilidade. Os esforços na melhoria da transmissão de conceitos contábeis relevantes precisam ser ainda mais intensificados em IES privadas e docentes precisam investir na sua formação acadêmica, evoluindo em busca do doutorado - o que contribui para elevar o domínio cognitivo de docentes e discentes, como aqui evidenciado.

A contribuição desta pesquisa para a discussão de aspectos conceituais para o processo ensino-aprendizagem em Contabilidade de Custos é de fundamental relevância, considerando a sua função principal de, conjuntamente com outras áreas de conhecimento, prover os gestores e demais usuários com informações que contribuam para o processo de tomada de decisão.

Espera-se que este trabalho contribua para o desenvolvimento das Ciências Contábeis, sugerindo novos estudos que se proponham a investigar a relação entre a Contabilidade e o seu ensino. Resta, por derradeiro, sugerir caminhos e tópicos para futuras pesquisas nesse campo e sua relação na extensão organizacional. Trabalhos futuros poderiam desenvolver propostas nessa linha, ajudando a construir arcabouço que solidifique o desenvolvimento cientifico da Contabilidade na busca de soluções de problemas concretos da sociedade.

\section{REFERÊNCIAS}

BROEDEL, A. L. (2002). A informação contábil e o mercado de capitais. São Paulo: Ed. Thomson. 
Conceitos relevantes de Custos: A visão de textos didáticos, o olhar da Teoria da Contabilidade e a percepção de discentes

Raimundo Nonato Lima Filho, Adriano Leal Bruni, Márcio Santos Sampaio, Antonio Gualberto Pereira

FASB - Financial Accounting Standards Board. Accounting Standards: Current Text, Vol. 1 General Standards Topical Index, John Wiley: New York, edition 2002/2003.

SFAS 5 Statement of Financial Accounting Standards n5. Accounting for Contingencies. Issued: March 1975, IN: Financial Accounting Standards Board Original Pronouncements. John Wiley: New York, edition 2002/2003.

GOULART, André Moura Cintra. (2008). Gerenciamento de Resultados Contábeis em Instituições Financeiras no Brasil. (Tese de Doutorado). Universidade de São Paulo USP.

. (2002). O Conceito de Ativos na Contabilidade: Um Fundamento a ser Explorado. Revista Contabilidade e Finanças - USP, São Paulo, n. 28, p. 56 - 65, jan./abr.

HENDRIKSEN, Eldon S., BREDA, Michael F. Van. (2007). Teoria da Contabilidade. Tradução de Antônio Zoratto Sanvicente. (5 ed.). São Paulo: Atlas.

HORNGREN, Charles T.; FOSTER, George; DATAR, Srikant M. (1997). Contabilidade de Custos. (9 ed.). Rio de Janeiro: Campus.

INEP - Instituto Nacional de Estudos e Pesquisas Educacionais. Disponível: <http://www.educacaosuperior.inep.gov.br/funcional/lista_cursos.asp>. Acesso: 04/mai/ 2009.

IUDíCIBUS, Sergio de. (2009). Teoria da Contabilidade. (9 ed.). São Paulo: Atlas.

KAM, Vernon. (1986). Accounting theory. New York, John Wiley \& Sons.

LEONE, George S. G. (2000). Curso de contabilidade de custos. (2 ed.). São Paulo: Atlas.

MAHER, Michael. (2001). Contabilidade de Custos. (1 ed.). São Paulo: Atlas.

MARTINEZ, Antônio Lopo. (2001). Gerenciamento dos Resultados Contábeis: Um estudo empírico das Companhias Abertas Brasileiras. (Tese de Doutorado). Universidade de São Paulo - USP.

MARTINS, Eliseu. (2005). Normativismo e/ou Positivismo em Contabilidade: Qual o Futuro? Revista de Contabilidade e Finanças, FIPECAFI, Vol. 3, №. 39, p. 3.

. (1998). Contabilidade de Custos. (6 ed.). São Paulo: Editora Atlas.

MEDEIROS, Luiz E. (1997). Análise de balanços: uma abordagem prática. (3 ed.). Porto Alegre: Ortiz. 
Conceitos relevantes de Custos: A visão de textos didáticos, o olhar da Teoria da Contabilidade e a percepção de discentes

Raimundo Nonato Lima Filho, Adriano Leal Bruni, Márcio Santos Sampaio, Antonio Gualberto Pereira

NIYAMA, Jorge. K, SILVA, César A. T. (2008). Teoria da Contabilidade. São Paulo: Atlas.

PEREZ, Marcelo Monteiro. FAMÁ, Rubens. (2006). Ativos Intangíveis e o Desempenho Empresarial. Revista de Contabilidade e Finanças - USP, São Paulo, n. 40, p. 7 - 24, Jan./Abr.

POMPERMAYER, Cleonice Bastos; LIMA, João Evangelista Pereira. (2002). Coleção Gestão Empresarial - FAE. Gazeta do Povo, volume 4.

SCHROEDER, R. G.; CLARK, M. W.; CATHEY, J. M. (2001). Financial Accounting Theory and Analysis. John Wiley \& Sons.

WATTS, Rose L., ZIMMERMAN, J. L. (1986). Positive Accounting Theory. Englewood Cliffs: Prentice Hall.

Data de Submissão: 06/11/2010

Data de Aceite: 22/11/2011 